\title{
DIREITO E JUSTIÇA EM SÃO TOMÁS DE AQUINO
}

\author{
Eduardo Carlos Bianca Bittar \\ Doutorando pelo Departamento de Filosofia e Teoria Geral do \\ Direito da Faculdade de Direito da Universidade de São Paulo
}

Resumo:

$\mathrm{O}$ autor aborda as principais contribuições que se podem lançar sobre a obra tomasiana, abordando a ética e o Bem no homem racional, o Direito e a Justiça natural, passando pelas suas variantes com término entre o injusto e os vícios da própria Justiça.

Abstract:

The author approaches about the most important contributions of Saint Thomas' work, and yet the ethics, the Good in the rational man, the Law and natural Justice, going through her variants, finishing on the unfair and vices of the own Justice.

Unitermos: Justiça natural, definição da lei, regime das leis.

Sumário:

1. Razão especulativa, razão prática e sindérese; 2. A ética e o Bem no homem racional; 3. Justiça natural e Direito; 4. A Justiça e suas variantes; 5. Finalidade e funções da lei; 6 . A definição da lei e seus elementos; 7. Relatividade e contingência da lei; 8. O regime das leis; 9. O injusto e os vícios da Justiça; 10. Aplicações práticas do conceito de Justiça; 11. Bibliografia.

1. Razão especulativa, razão prática e sindérese

Para que possamos apreender com precisão o conceito de Justiça (iustitia) e a sua aplicação entre os homens, excluindo-se, portanto, do âmbito de interesse desta pesquisa qualquer remissão mais aprofundada a discussões sobre a Jústiça metafísica, como o é a discussão sobre a Justiça dos atos de Deus (Dicendum quod necesse est quod in quolibet opere Dei misericordia et veritas inveniantur- 
Sum. Theol., quaest. XXI, art. IV), no contexto da philosophia perennis aquiniana, necessário se faz analisarmos a faculdade que distingue o homem dos demais seres: a razão (ratio).

O homem é composto de corpo e alma, sendo o primeiro a matéria perecível que colabora para o aperfeiçoamento da alma, criada por Deus. A alma é incorruptível, imaterial e imortal e relaciona-se com o corpo da seguinte forma: " $a$ alma está para o corpo assim como o ato está para a potência" A alma constitui-se num princípio vital que distingue os seres conforme o grau evolutivo, assim:

a. a alma vegetativa compõe os vegetais, que simplesmente executam as atividades das quais desconhecem a forma e o fim; são essencialmente materiais;

b. a alma sensitiva compõe os animais, seres irracionais, que, dotados de sensibilidade, executam e apreendem a forma do agir;

c. a alma intelectual é inerente aos animais racionais, capazes de executar, apreender a forma e o fim de suas ações; essa alma é de essência puramente espiritual.

Assim, enquanto o mais perfeito dentre os seres materiais, o homem, acumula as três faculdades a saber, a vegetativa, a sensitiva e a intelectual -, sendo que a última o particulariza e torna-o capaz de conhecer o fim de suas ações, os demais seres da scala naturae se limitam, no máximo, a reunir em sua estrutura intrínseca duas destas potências, como é o caso dos animais. As formas angélicas, por sua vez, estão destituídas de corporeidade, pairando independentemente do grilhão corporal, o que as afasta da área de interesse deste estudo.

Se a razão foi localizada, pode-se dizer, com São Tomás de Aquino, depurando-se este conhecimento, que a inteligência é "a faculdade espiritual capaz de ultrapassar os dados sensiveis e de penetrar na essência das coisas capaz de ler no interior dos seres"

Desta forma, seguindo o princípio do conhecimento descrito na definição escolástica de que nihil est in intelectu quod non prius in sensu, verificamos que se faz necessária a faculdade sensitiva para que haja o conhecimento e a apreensão do sentido da realidade. Parte-se do material para que se alcance o abstrato, do particular para que se alcance o geral. O método do conhecimento aqui referido radica-se nos principais postulados da filosofia aristotélica (De anima; Parva Naturalia; Analytica Posteriora), essencialmente empírica e sensitiva.

Também, pode-se dizer que o homem tem o princípio de seus movimentos em si mesmo, mas, diferentemente dos animais, consegue discernir os 
fins aos quais almeja. Daí, falar-se na participação conjunta da vontade com a inteligência, de maneira que a causa final (inteligente) move a causa eficiente (vontade) e vice-versa. Deus lançou no homem, como motor universal que é (Motor Imóvel), a vontade para que siga no sentido do Bem (o próprio Deus). A inteligência consiste, então, num bem particular de pequena participação no bem universal que é Deus, ou, ainda, no dizer de Aristóteles: "o princípio do ato da inteligência é mais elevado que a inteligência, é Deus"

A possibilidade humana de escolher entre valores diametralmente opostos, a verdade real ou a verdade aparente, comprova a existência do livre arbítrio (liberum arbitrium), ou seja, da capacidade de julgar aquilo que é certo e aquilo que é errado, noção esta secularmente explorada, inclusive com valiosas contribuições da doutrina agostiniana. A nobreza do ato moral consiste em, através da inteligência, discernir o Mal do Bem e executar o escolhido através da vontade, destinando-se para um determinado fim -- o télos da filosofia peripatética. $\mathrm{O}$ ato moral de escolha do Bem é puramente racional. Mas como se alcança a racionalidade? Seguindo o pensamento escolástico-tomista, através da experiência.

$\mathrm{O}$ indivíduo, enquanto ser ético particular, une-se aos seus semelhantes no convívio social, pois racionalmente destina-se ao seu fim, mais facilmente alcançável pelo esforço e colaboração conjunta. É a sociedade. Mas esta nada mais é do que um agregado composto de várias unidades familiares, esta a mais natural e primeira forma de convívio humano, dirigida por uma autoridade que deverá ser prudente na escolha dos meios que conduzirão ao Bem Comum. Percebe-se nitidamente que o Doutor Angélico segue de perto o pensamento aristotélico no que concerne à ética do coletivo. Esta atitude faz, portanto, da racionalidade partilhada o motor para o alcance do Bem Comum.

Ainda podemos dizer que a faculdade intelectiva, una e indivisa, age de duas formas: segundo a razão especulativa, ou seja, procura do conhecimento pelo conhecimento; segundo a razão prática, que tem por fim último a ação (execução, efetivação, atualização). É sobre o agir, sobre a razão prática que a ética incide. Na filosofia tomista este conceito encontra-se sob a denominação de sindérese (sinderesis), conjunto de conhecimentos genéricos e abstratos conquistados a partir da experiência habitual que norteia o ser na escolha e no discernimento entre o Bem e o Mal. Conclui-se, já neste passo da investigação, que o homem participa ativamente do mundo através da razão especulativa, procurando a descoberta e o entendimento das leis que regem o mundo e o cercam, e da razão 
prática, agindo prudentemente no relacionamento com seu próximo, ou mesmo, no sentido de dominar a sua natureza instintiva: sibi ipsi et alliis providens (Sum. Theol., I-II, q.91, a.2). Isso é o que se pode chamar de uma verdadeira lex ethica naturalis, que não deixa de corresponder a uma participação da lei eterna. Ainda aqui se vêem ecoar as palavras aristotélicas inscritas na Ethica Nicomachea (livro VII), que preceituam uma doutrina que faz do agir ético um agir pendular entre o vício e a virtude e se lastreia na escolha entre a dor e o prazer.

Toda esta especulação faz crer que o imperativo da razão sendo a distinção entre os seres, a capacidade de discernir, de escolher e de optar, far-se-á conduzir de acordo com o que esta mesma razão, por meio de seus processos seletivos de conhecimento, apreende como melhor. Este algo melhor deverá, para o homem, certamente, distar do que seria o melhor para o animal, para o que o concurso da racionalidade, imperando por sobre a instintividade, a impulsividade e a paixão intestina, se faz de grande importância. Reminiscências platônicas na dicotomia irascível/racional podem aqui ser radicadas.

\section{A ética e o Bem no homem racional}

O homem, como ser racional por natureza, dotado de faculdades apetitivas e intelectuais próprias, é capaz de agir segundo as orientações dadas por ambas as faculdades. Assim, a sindérese (sinderesis) atua, para o ser agente, de modo a estabelecer o fim da razão prática, ou seja, o Bem. Mas o que é o Bem que guia a ação como causa final? O conceito, já definido anteriormente por Aristóteles, é: bonum est quod omnia appetunt. Assim, todo ser tem como fim o Bem, e o desejo maior de cada um é a atualização deste último, donde podemos afirmar que não existe o Mal como fim de uma ação, pois o Mal é a simples privação do Bem. Mais ainda, Aquino nega uma ontologia ao Mal, fazendo deste um estado de ignorância do Bem (Dicendum quod, sicut ex dictis patet, malum quod in defectu actiones consistit semper causatur ex defectu agenti - Sum. Theol., quaest. XLIX, art. II; Unde, cum malum sit privatio boni... - Sum Theol., quaest. XLIX, art. IV; Dicendum quod nullum ens dicitur malum per participationem, sed per privationem. Unde nono oportet fieri reductionem ad aliquid quod sit per essentiam malum - Sum Theol., quaest. XLIX, art. IV).

Todo o conjunto sinderético de informações acumuladas forma um grupo de princípios, que não são inatos, mas sim conquistados a partir da 
experiência, que dirige a razão prática. O primeiro princípio da razão prática, assim dirigida em sua finalidade, será fazer o Bem e evitar o Mal (bonum faciendum et male vitandum), ou, nos próprios termos do Aquinatense: Et ideo primum principium, in ratione practica, est quod fundatur supra rationem boni; quae est: bonum est quod omnia appetunt. Hoc est ergo primum praeceptum legis, quod bonum est faciendum et prosequendum et malum vitandum (Sum.Theol., I-II, q.94, a.2). O homem se guiará por princípios imanentes hauridos a partir da experiência que formam o que se pode chamar de uma lei natural, verdadeiro hábito interior. Esta lei natural apresenta características básicas, a saber:

a. é racional: rationis prima regula est lex naturalis, uma vez que é fruto da razão prática e sinderética do homem;

b. é rudimentar, ou seja, só pode ser considerada como princípio norteador ou origem do Direito, não correspondendo à sua totalidade;

c. é insuficiente e incompleta, pois necessita do Direito Positivo, do qual é diretriz, para efetivar-se.

A conclusão é a de que é uma relação de débito recíproco entre o homem social e seu semelhante que dá lugar à existência da Justiça dentro da comunidade civil. $^{1}$

\section{Justiça natural e Direito}

Do que já foi dito até o presente momento, verificamos que São Tomás de Aquino, seguindo as lições do Philosophus, ${ }^{2}$ aplicou em seu sistema filosófico a categoria do justo meio entre extremos opostos (mesotés), pois numa perfeita composição fornece à lei natural dois elementos que se conjugam harmonicamente: o racionalismo e a experiência (empeiría).

Por outro lado, formalmente falando, identificamos o justo e o bem como imutáveis, tidos em consideração absoluta e universal. Mas, materialmente falando, o justo e o bem assumem um caráter relativo, uma vez que, a partir do

I. "Iustitia autem proprie dicta debitum necessitatis requerit: quod enim ex iustitia dicui redditur, ex necessitate iuris ei debetur" Ainda: "Iustitia enim, secundum Philosophum, in V Ethic., ad alterum est, cui debitum reddit" (Sum. C. Gent., cap. XXVIII, II, 1). E mesmo, "Cum iustitiae actus sit reddere uincuique quod suum est". (Sum. C. Gent., cap. XXVIII, II, 2).

2. "Et ideo medium iustitiae consistit in quadam proportionis aequalitate rei exterioris ad personam exteriorem. Aequale autem est realiter medium inter maius et minus; ut dicitur in $\mathrm{X}$ Metaph. (lect. VII)" (Sum. Theol., quaest. LVIII, art. X). 
momento em que são instituídos pelo homem, tornam-se contingentes no tempo, no espaço e segundo as variações da natureza humana (Sum. Theol., I-II, q. 57, art. 2).

Desta maneira, concluímos que a lei natural é formada por dois tipos de princípios:

a. prima praecepta, que são os princípios sinderéticos imutáveis e universais;

b. praecepta secunda, que compõem a parte mutável do justo natural, consistindo em conclusões retiradas dos princípios primeiros. O ordenamento éticojurídico parte do necessário para estabelecer conclusões e, como tudo o que é contingente, ${ }^{3}$ varia no tempo.

O justo natural diz respeito a homens e animais, quando tomado em uma consideração absoluta, mas apenas ao homem, quando existe um relacionamento do ato com suas conseqüências, mérito da faculdade racional humana capaz de estabelecer relacionamentos do tipo causa-efeito.

A Justiça (iustitia) e o Direito (ius) se interelacionam, sendo que o Direito visa a poder estabelecer de maneira plena a Justiça. Logicamente, não são e não significam o mesmo. Mas o justo natural não pode estar plenamente contido no Direito. O Direito não é a Justiça, virtude moral maior, ${ }^{4}$ mas busca a mesma, não sendo o método dedutivo (silogismo) o mais apropriado nesta busca, pois algo que é sinderético só pode ser alcançado através da experiência empírica, e, portanto, através do método indutivo (do particular para o todo).

A lei natural (lex naturalis), como manifestação da lei eterna no mundo (lex aeterna), sorte de reificação racional-material de algo que possui quintessência espiritual, tem uma amplitude maior que a da moral, e esta, por sua vez, engloba o Direito. A Justiça moral demanda a adequação de todo ato humano ao seu fim e a forma como é executado este ato, enquanto que a Justiça legal se refere apenas ao ato exigido para o cumprimento de deveres sociais. Estes impõem ao homem uma conduta externa, e é aqui que aparece a prescrição legislativa, estabelecendo obrigações, criando situações, proibindo condutas (Sed materia iustitiae est exterior operatio, secundum quod ipsa vel res cuius est usus, debitam

3. "Dicendum quod ratio humana non potest participare ad plenum dictamen rationis divinae, sed, suo modo, et imperfecte" (Sum. Theol., q. XCI, I-II, art. 3).

4. "Unde et iustitia legalis, secundum quod ordinat ad bonum commune, potest dici virtus generalis... Esta frase demonstra a magnitude da Justiça legal, e isto por ordenar toda a comunidade civil ao Bem Comum (Sum. Theol., II-II, q. LVIII, art. 6). 
proportionem habet ad aliam personam - Sum. Theol., quaest. LVIII, art. X). Também o Direito Positivo requer a atuação de uma autoridade que o institua, dando-Ihe força coativa, enquanto que o Direito natural é algo que advém da razão humana e tem força própria dada pela natureza. Aqui se pode constatar a presença espectral da recorrente oposição katà physin/ katà synthèken, de sede aristotélica, entre o que é por natureza e o que é por força da técnica humana, a iluminar a explanação da temática.

\section{A Justiça e suas variantes}

As inúmeras classificações do ius ou do iustum apresentadas por São Tomás de Aquino representam a fusão da conceituação dada pelos jurisconsultos romanos e daquela dada por Aristóteles (Ethica Nicomachea, livro V), esta última sempre presente e muito influente sobre o pensamento tomasiano em função de seu comprometimento com a filosofia peripatética, sobretudo em função de seus comentários à obra de Aristóteles (La justicia: comentários a el libro quinto de la Ética a Nicómaco, trad. de Benito R. Raffo Magnasco, Argentina, 1946). De um lado, o filósofo grego entendia o justo político (dikaion politikón) como gênero maior capaz de englobar o justo legal (dikaion nomikón), e o justo natural (dikaion physikón), este próprio da natureza racional do homem. Então, o justo, em Aristóteles, obedece à seguinte árvore semântica, extraída da leitura do Livro V da Ethica: 1. justo total (díkaion nomimón); 2. justo particular (díkaion íson); 2.1. justo distributivo (dikaion dianemetikón); 2.2. justo corretivo (diorthótikon dikaion); 2.2.1. justo comutativo; 2.2:2. justo na relações não-voluntárias; 3 . justo político (dikaion politikón); 3.1. justo legal (dikaion nómikon); 3.2. justo natural (díkaion physikón); 4. justo doméstico (oikonomikòn díkaion); 4.1. justo despótico (despotikòn dikaion); 4.2. justo conjugal (gamikòn díkaion); 4.3. justo paternal (patrikòn dikaion). De outro lado, divergindo da posição aristotélica, os jurisconsultos romanos entendiam ser o ius passível de divisão em ius naturale, de acordo com a natureza animal do homem, de onde se origina o ius gentium, que, segundo a definição de Gaio quasi quo iure omnes gentes utuntur -, é o direito comum a todos os homens, e ius positivum, próprio da natureza racional do homem e sujeito a variações de acordo com a localidade onde se desenvolve.

Nos esforços de conciliação das concepções filosófica grega e jurídica romana, o Doutor Angélico acaba por elaborar não apenas uma conceituação eclética 
a partir da mera fusão de ambas, mas uma teoria própria, na qual se congregam elementos da filosofia, da metafísica e do Direito, sem que se perca a noção da realidade e da imperiosa necessidade de efetivação da Justiça. E para esta concepção, a Justiça é uma virtude cardeal, e sua função consiste em dar a cada um o que é seu (Ergo non sufficienter, per hoc, notificatur actus iustitiae, quod dicitur actus eius esse reddere unicuique quod suum est - Sum. Theol., quaest. LVIII, art. $\mathrm{XI})$.

E, nesta dimensão, para tudo há uma diretriz, que nos é dada pela lei eterna; a ordem, desejando-se ou não, existe e é imperativa, regente do todo, a partir da razão divina, que a tudo inspira. A lei eterna é o princípio e o fim do todo universal, pois, como diz São Tomás: "todo o conjunto do universo está submetido ao governo da razão divina" (Sum. Theol., I-II, q. 91, art.1, resp.).

Daí decorre, de maneira imediata, que uma coisa pode ser adequada a um homem pela própria natureza da coisa, configurando o direito natural, por exemplo, quando no relacionamento entre indivíduos dá-se $\mathbf{x}$ para receber $\mathbf{x}$. E, ainda, que uma coisa pode ser adequada a um homem pelo estabelecimento de uma convenção, particular ou pública, conforme tenhamos um pacto limitado a relações inter-individuais ou consentimento geral dado pelo povo ou ordenado pelo príncipe que representa esse povo. Temos, assim, o Direito natural e o positivo.

O Direito natural, como categoria muito larga, recebe subclassificações, a saber:

a. ius naturale strictissimo modo, ou seja, a parte do Direito natural comum a todos os homens e animais ou, ainda, quod omnia animalia docuit;

b. ius gentium, que a modo de conclusão se deduz do Direito natural e consiste em capacidade exclusiva do homem, animal racional. Mas o ius gentium não se apresenta derivado unicamente do Direito natural, também do Direito Positivo, deduzido de modo conclusivo e consubstanciado em leis escritas-positivas.

O ius positum, por sua vez, à maneira de determinação, é derivado do Direito natural. É absolutamente imprescindível a sua existência em função da necessidade de aplicação da Justiça inter homines. O homem, encontrando-se no mundo terreno em companhia de seu semelhante, necessita de regras convencionais positivas para que possa garantir a pacificidade dessa interação no meio social. $O$ Direito natural, enquanto categoria sinderética de princípios imanentes ao homem, é insuficiente, necessitando de leis positivas complementares (lex, o Direito escrito), 
que acompanham as variações da natureza humana, suas imperfeições e as contingências oriundas da limitação do saber racional.

O Direito positivo, se adequado ao Direito natural, é um benefício para a comunidade civil, mas se estiver baseado na perversão da reta-razão (recta ratio), sendo-lhe uma corruptela, constituir-se-á em costumes irracionais e leis injustas, sem força coativa dada pela natureza (Sum. Theol., I-II, q. 96, art. 4), mas somente por convenção.

Assim, de maneira sucinta, quando se fala em ius podem-se detectar as seguintes categorias:

a. ius naturale: comum a homens e animais;

b. ius gentium: racional, comum a todos os homens;

c. ius positivum: puramente convencional e relativo, assim como altamente contingente.

A Justiça legal, por sua vez, é aquela que diz respeito, imediatamente, ao Bem Comum (convívio pacífico na sociedade civil) e, mediatamente, aos particulares. Justamente por não abranger todas as virtudes, por ter seu âmbito de atuação limitado às relações que interessam à sociedade como um todo (nem todo vicío será digno de punição, apenas aqueles que atentarem diretamente contra o desenvolvimento do meio social), a Justiça legal é completada pela Justiça particular. Esta última é responsável pela ordenação dos indivíduos na relação com os particulares, tendo, portanto, reflexos mediatos sobre o Bem Comum e imediatos sobre os particulares. É assim que verificamos a importância da existência do justo legal para "ordenar os bens particulares ao Bem Comum" (Sum. Theol., II-II, q.61, art.1), complementado pelo juízo particular, referente à distribuição do que é devido a cada um segundo o objetivo social maior, ou seja, o Bem Comum, visando ao particular como singular dentro do todo.

Categoria de relevo dentro da doutrina tomista é aquela atinente à diferenciação entre Justiça comutativa e distributiva. A primeira é responsável pela regulação das relações entre particulares, entre as partes individuais componentes da esfera maior da sociedade. A segunda coordena o relacionamento da parte com o todo, de modo a atribuir a cada parte o que lhe é devido segundo seu mérito, capacidade ou participação dentro da sociedade. ${ }^{5}$

5. "Potest autem ad aliquam partem duplex ordo attendi unus quidem, partis ad partem; cui similis est ordo unius privatae personae ad aliam. Et hunc ordinem dirigit commutativa iustitia, quae consistit in his quae mutuo fiunt inter duas personas ad invicem alius ordo attenditur totius ad 
Em ambos os casos a Justiça encontra-se presente como meio de equilíbrio na interação, estabelecendo a igualdade entre aqueles que se relacionam. Mas os critérios de igualdade diferem em um e outro caso. Destarte, na Justiça comutativa, das trocas, o critério de igualdade utilizado é o da média aritmética, ou seja, divisão em quantidade no exato meio. Por exemplo, numa compra e venda, se o comprador, após efetuada a negociação, permanecer com seis unidades de referência e o vendedor com quatro, existirá desigualdade, que será mediada pela Justiça comutativa de modo a que cada um receba cinco unidades, valores idênticos segundo uma média aritmética. Na Justiça distributiva, consistente na repartição dos bens dentro da coletividade segundo a maior ou menor participação meritória de cada qual, o critério de igualdade é a proporcionalidade, ou ainda, a proporção geométrica. ${ }^{\circ}$ Isto demonstra a expressão da participação da doutrina aristotélica no pensamento do Aquinatense, uma vez que estas noções aqui expostas se encontram cristalizadas na obra do Philosophus grego (Ethica Nicomachea, liv.V. III). O que diferencia a opinião de ambos os pensadores é que o filósofo peripatético dividia a Justiça legal, parte da Justiça social, em distributiva e corretiva, sendo que esta última abrangia as justiças comutativa e judicial. Para São Tomás, além de outras pequenas minúcias, fica suprimida a categoria da Justiça corretiva, igualando-se a esta a comutativa, restando apenas uma divisão global.

5. Finalidade e funções da lei

O Direito depende da lei para se consubstanciar no meio social. Mas a lei não é o Direito mesmo (Et ideo lex non est ipsum ius, proprie loquendo; sed aliqualis ratio ius - Sum. Theol., quaest. LVII, art. II). É pelo intermédio da Justiça, ideal do Direito, que a lei causa o Direito. A lei escrita vem a ser uma composição que reúne elementos de Direito natural e de Direito Positivo, e o faz inscrevendo-se entre os homens, intervindo nas relações humanas. Isto ocorre devido à necessidade

partes; et huic ordini assimilatur ordo eius quod est commune, ad singulas personas" (Sum. Theol., II-II, q. LXI, art. 1).

6. "Et ideo in iustitia distributiva non accipitur medium secundum aequalitatem rei ad rem; sed secundum proportionem rerum ad personas..." Ainda: "Et ideo dicit Philosophus, lib. V Ethic. (op. cit.), quod tale medium est secundum geometricam proportionalitem, in qua attenditur aequale non secundum quantitatem sed secundum proportionem" (Sum Theol., II-II, q. LXI, art. 2). 
de que o que está positivado obedeça aos princípios naturais humanos para que esteja ordenado segundo a reta-razão (recta ratio), da ordo naturalis.

A finalidade da lei positiva é conduzir o homem para a virtude, ordenar as condutas dirigindo-as para o Bem Comum. Mas a lei não está adstrita a tornar imediatamente o indivíduo particular virtuoso; a lei visa a tornar o meio social pacífico o suficiente para que seja favorável à proliferação e ao cultivo das virtudes. Nas palavras de Aristóteles, a lei forma o bom cidadão, e não o homem bom, mas o bom cidadão pode vir a se tornar um homem bom, que é aquele que age retamente independentemente de ser ou não forçado por leis. ${ }^{7}$ Destarte, a lei não proibirá todos os vícios ou tudo aquilo que contrarie qualquer virtude, mas apenas os vícios que atentem contra o conjunto social. O particular estará adstrito à lei apenas no que concerne à necessidade de manutenção de virtudes conexas com o todo; nem todos os seus vícios serão recriminados, apenas aqueles que atingirem a outrem ou obstruírem o desenvolvimento da sociedade. A lei se preocupa com o interelacional, com a conduta externa.

É de acordo com essa finalidade maior que a lei desempenha suas funções precípuas, como:

a. imperare: ordenar determinada conduta;

b. prohibere: proibir aquilo que possa ser prejudicial ao convívio

social;

c. permittere: não proíbe a conduta e, ao mesmo tempo, não obriga, dando espaço para a escolha entre fazer e não-fazer aquilo que é permitido;

d. punire: incidência da sanção quando da violação do princípio proibido.

Quanto a este último item, verifica-se sua eficácia na coação pelo temor que provoca (cogens metu poenae). O indivíduo, coagido pelo temor da sanção legal, será forçado a ordenar-se ao Bem Comum, podendo, desta forma, habituar-se a viver na virtude (a lei estará desempenhando uma função educativa, contribuindo mediatamente para o progresso do indivíduo), fazendo-se, então, na linguagem aristotélica, do bom cidadão, um homem born. Mas a punição é própria

7. A respeito, anteriores reflexões já lançadas no Colóquio Direito e Virtude, 25 e 26 de abril de 1997 (dia 25, 141100), sob o título O homem bom e o bom cidadão na Ethica Nicomachea, na FFLCH. Departamento de Filosofia, Universidade de São Paulo, nos levaram a estas mesmas conclusões, discernindo-se as sutilezas também aqui expressas no texto tomasiano. 
do Direito Positivo, não existindo qualquer fundamentação segundo o Direito natural.

\section{A definição da lei e seus elementos}

De maneira sucinta, a lei consiste numa "ordenação da razão para o Bem Comum, promulgada pelo chefe que governa a comunidade". Este discurso, não-obstante sintético, congrega os elementos, e não só alguns, mas todos os possíveis, necessários e fundamentais, que compõem o conceito de lei, segundo o Doutor Angélico. Iremos analisar mais detidamente cada um dos elementos que participam da essência do conceito de lei. Assim:

1. "A lei é uma ordenação da razão": a razão permite ao homem o discernimento entre o Bem e o Mal. A razão prática atuará no sentido de direcionar o homem, através de conceitos abstratos, gerais e sinderéticos, para o seu fim: o Bem. Para que um conjunto de atos se ordene ao Bem, é necessária a escolha dos meios mais apropriados para a consecução deste fim, ou seja, aqueles que estão segundo a reta-razão ordenados com o Bem.

No meio social, caberá ao legislador agir com prudentia na escolha dos meios máis apropriados para que se alcance o fim social, que é o Bem Comum.

Podemos discriminar o fim humano da seguinte maneira: segundo uma regra próxima que guia a vontade para o Bem; segundo uma regra primeira ou suprema que é a lei eterna ou divina. Assim, segundo a regra próxima, a lei ordena para a tranqüilidade temporal da cidade - legis humanae finis est temporalis tranquilitas civitatis (Sum. Theol., I-II, q.98, art. 1). Segundo a regra suprema, dirigimo-nos para a felicidade total, para confundirmo-nos na universalidade do próprio Deus, no dizer do Doctor Angelicus: Deus est primum principium omnis boni.

A razão única, agindo através do intelecto prático, é a lei natural que se destina aos fins próprios, contingentes e relativos como tudo o que é humano; agindo através do intelecto especulativo, contempla a verdade universal, buscando o interior de si mesma. Mas a intercomunicação entre razão prática e especulativa permite que tenhamos a participação da lei natural na lei universal e a busca de fins que acabam por se confundirem.

2. "promulgada": a lei positiva que visa ao alcance do Bem Comum deve ser promulgada, ou seja, tem de ser-Ihe dada publicidade para que se torne 
acessível a todos aqueles que comungam de um convívio social. A lei promulgada não pode ser ignorada pelo homem por ser racional e capaz de discernir, ao contrário do animal irracional, que não age como senhor de seus instintos. O grande mérito da ação moral humana está em, através do livre arbítrio, optar por fazer o Bem e evitar o Mal, de acordo com a reta-razão e o princípio do justo meio virtuoso aristotélico. $\mathrm{O}$ desconhecimento da lei só pode ser alegado por aquele que ficou impossibilitado de conhecê-la por estar isolado, encarcerado...

3. "pelo chefe que governa a comunidade": o todo deve legislar para as partes. Assim, o chefe, como representante do todo, deve legislar para que as condutas particulares se ordenem ao todo. O particular não pode legislar, apenas emitir conselho. É o caso do pater familias, que estabelece normas de caráter familiar que não podem ter o caráter de leis, pois a familia é a parte no conjunto social, e a parte deve ordenar-se àquilo que é geral ou represente o interesse do todo.

4. "para o Bem Comum": a lei deve conduzir ao Bem Comum como finalidade. O Bem Comum é algo que não se confunde com a mera somatória dos bens particulares daqueles que estão agregados numa sociedade, mas é algo que supera e transcende essa somatória. Os indivíduos que fazem parte desse conjunto preservam a qualidade de seres livres e independentes, devendo colaborar para a consecução do escopo maior. A Justiça legal tem como finalidade imediata o Bem Comum, mas tendo em vista que a sociedade é formada por seres singulares, estes se beneficiam da organização e do convívio virtuoso, exercendo a lei um papel indireto ou mediato de auxílio ao particular. ${ }^{8}$

O justo legal, segundo o Doutor da Igreja, que retoma a tripartição do Philosophus grego, pode ser exercido de três formas:

a. por leis comuns: atingem todos os cidadãos, indistintamente;

b. por privilégios: são leis dirigidas a particulares em casos especiais, proporcionalmente;

c. por sentenças: aplicação da própria legislação.

Ainda podemos dizer que o fím último de todos os seres é o Bem Comum transcendental, i.e., a própria Providência Divina. Daí a imperiosa necessidade de que a lei natural, assim como a lei positiva, estejam de acordo e participem da lei eterna. O Bem particular transcendental é o direcionamento do individuo a Deus, segundo a regra suprema que rege o apetite humano. Assim:

8. Cfr. Correia, Ensaios politicos e filosóficos. 1984 
a. Bem comum transcendental: destino de tudo;

b. Bem particular transcendental: deve ordenar-se unicamente ao Bem comum transcendental;

c. Bem comum temporal: é subordinado aos dois anteriores, mas subordina o Bem particular temporal;

d. Bem particular temporal: é o Bem do particular na realidade temporal e contingente e subordina-se a todos os precedentes.

$O$ chefe da comunidade civil deve empenhar-se em instaurar, promover e conservar a ordem, buscando ordenar a unidade social, obedecendo a três objetivos: a paz, a vida virtuosa dos cidadãos e a atribuição de bens materiais úteis para o desenvolvimento social. Os deveres do chefe da comunidade, orientados segundo a reta-razão, são os de suprir aquilo que falta, aprimorar o existente e corrigir o desordenado, para que o corpo possa caminhar num único e harmonioso ritmo, para que se realize o objetivo almejado, ou seja, a felicidade da comunidade. Mutatis mutandis, era esta a proposta aristotélica: realizar a eudaimonía da pólis por meio de um viver ordenado e racional, que podia se realizar espontaneamente pela simples amizade (philía), ou ainda, suprida pela Justiça como virtude (dikaiosýne).

Assim, no conjunto da filosofia tomista, como no da aristotélica, a política, a ética e a Justiça estão profundamente imbricadas, de modo a constituírem conhecimentos indissociáveis, a exemplo do que ocorre com os líquidos imiscíveis.?

\section{Relatividade e contingência da lei}

No mundo ocorrem duas espécies de fatos, que são o acidente e o fato natural. Este último obedece a princípios rígidos, inflexíveis de causa e efeito, de modo a permitir a previsão da ocorrência desses fatos a partir da simples observação da lei que o rege. A lei de causalidade só é desrespeitada quando da ocorrência do caso fortuito. Isto, em apertada síntese para o que segue.

O acidente (accidens), por sua vez, é uma espécie de fato que não se caracteriza por ser de absoluta e imperiosa ocorrência, mas pela relatividade e

9. Também. a respeito, anteriores reflexões já expostas e publicadas nos Anais do VIII Encontro Nacional de Filosofia da ANPOF Caxambu. 25 e 30 de sctembro de 1998, sob o titulo de Poder e legitimidade na teoria politica aristotélica (pp. 95-96). realização conjuunta da ANPOF, da UNICAMP e da USP, com apoio do CNPq. da FAPESP. da I:APEMIG, do CAPES e da FINEP. nos levaram a estas mesmas conclusões. 
contingência. Assim como a regularidade está para a previsibilidade, o acidente está para a imprevisibilidade. A ordem ético-jurídica, que trabalha com a conduta dos seres humanos, assim como todas as ciências sociais (assim ora chamadas as ciências do espírito), caracteriza-se por ser fruto da razão prática humana, ou seja, derivar de uma potência não só dependente, como também contingente. Não se pode prever todo tipo de acontecimento, dado o surgimento constante de novos fatos, novos problemas e novas ações numa sociedade permanentemente em evolução. As contingências obedecem a:

a. condições temporais: gradatim ad imperfecto ad perfectum, o homem caminha lenta e gradativamente do imperfeito para o perfeito com o decurso do tempo. Assim podemos verificar que caminhamos de legislações mais rudimentares para outras mais avançadas e, portanto, mais de acordo com a lei natural;

b. condições pessoais: de acordo com a maior ou menor capacidade humana de domínio sobre as paixões e os maus costumes, de acordo com a própria capacidade de compreensão variável de indivíduo para indivíduo. Assim, verbi gratia, uma alma jovem, por ser pouco experiente, tem uma capacidade de compreensão das ciências práticas (philosophia) muito menor que as almas mais experientes;

c. condições circunstanciais: variabilidade da natureza humana na determinação do conjunto de valores que definem aquilo que é justo e aquilo que é injusto. A natureza humana varia de uma localidade para outra, daí a necessidade imperiosa de que se estabeleçam leis adequadas a cada região, não existindo leis positivas universais e absolutas.

Todas as variações que possam ocorrer com uma lei ou são de acréscimo ou são de subtração. Destarte, a parte contingente da lei natural é a que decorre dos praecepta secunda, ou seja, conclusões retiradas dos prima praecepta, que são absolutos. A razão e o conhecimento humano alargam-se com o decorrer dos séculos e, como as conclusões só podem ser estabelecidas a partir do trabalho racional, conclui-se que a capacidade de extrair, a partir da lei natural (lex naturalis), conclusões aplicáveis à realidade dependerá do grau de evolução sinderético do ser humano. Filosoficamente, são essas conclusões variáveis extraídas a partir da mesma lei natural que informam o conteúdo da lei positiva.

São Tomás de Aquino, utilizando-se de profundo senso realista, em muito conseqüência dos estudos e investigações acerca de Aristóteles, afirma 
categoricamente que o legislador não pode prever todos os casos que venham a ocorrer futuramente, tendo seu alcance limitado aos casos mais comuns. Se uma situação econômica surgir, por exemplo, deve-se preferir a lei omissa ou defasada para que se procure o Bem Comum. É nesse momento que a necessidade supera a lei, ensejando o nascimento do direito de desobedecer a lei, direito este exercitável por qualquer um, não dependendo da decisão do chefe da comunidade ou do legislador. Aqui há um ingrediente não-presente na teoria peripatética - pois, na Ethica a lei é posta para a defesa e segurança da comunidade política (dikaion nomimón, ou justo total), cujo desrespeito importaria na quebra do que é para todos -, ou seja, a garantia tomasiana da existência de um direito à resistência civil.

O que é natural ao homem pode falhar, pois muitas vezes pode não se adequar ao Bem Comum, que é a finalidade do próprio conjunto social. Aquilo que é contingente pode ser genericamente correto, mas não se adequar a casos particulares. Aristóteles, a este respeito, já dizia: "Não devemos buscar o mesmo grau de certeza em todas as coisas" (Ethica Nicomachea, l, cap. III, n. 1). Reiterando a posição do filósofo, o Aquinate afirma também: "E sucede com freqüencia que a observância de algum ponto da lei é útil à saúde comum e prejudicial em alguns outros" (Sum. Theol., I-II, q. 96, art. 6); ou ainda: "natura autem omnis est mutabilis. Et ideo id quod naturale est homini, potest aliquando difecere" (Sum. Theol., II-II, q. 57, art. 2).

\section{O regime das leis}

O que é mais conveniente para a comunidade civil, estar sob um regime de leis ou de homens? Esta é uma questão clássica, que pasmou a Antigüidade por séculos, tendo sido recorrente recurso de argumentação entre os círculos sofistas. Por sua vez, elucidando a questão, o Doctor Angelicus, repudiando a paixão, opta pela mesma posição de Aristóteles (Politica, 1.287 a; 1.287 b) e de Platão (Leis, 644 D; 645 A; 674 B): o regime das leis. As razões para essa escolha são desta maneira apresentadas:

a. numa sociedade ampla, existe a necessidade de que os juízes sejam numerosos para que exista a verdadeira efetivação da Justiça. Destarte, é muito mais fácil que se encontrem poucos bons legisladores do que muitos juízes que possam ser considerados bons para o exercício do cargo; 
b. o legislador (legislatoris), ao exercer sua função legiferante, procura prever os casos acessíveis à capacidade humana em momento anterior ao da ocorrência dos fatos. O juiz, por sua vez, irá analisá-los no momento de sua emergência. Se o juiz estiver submisso à lei, irá apenas executá-la;

c. o juiz (iudex), diante do fato, pode envolver-se subjetivamente no caso, sendo conduzido e deixando-se cegar pelo amor, pelo ódio, pelas paixões... deixando de existir a objetividade necessária à segurança de um julgamento apropriado. $\mathrm{O}$ legislador produz o corpo legislativo em abstrato, estando distante da ocorrência dos fatos que poderiam influenciá-lo.

$\mathrm{O}$ objeto da Justiça é o Direito (Et hoc quidem est ius. Unde manifestum est quod ius est obiectum justitia - Sum. Theol., quaest. LVII, art. I), que, por sua vez, é o efeito da lei. O ato da Justiça é o ato de julgar. Verificamos que o julgamento é algo imprescindivel para a administração da Justiça entre os homens desde que: proceda de uma inclinação justa, do contrário será injusto; proceda de uma autoridade competente e instituída para o desempenho da função judicante, caso contrário será usurpada a sentença; seja proferida a sentença de acordo com a recta ratio, que guia a prudência do juiz, pois senão estaremos diante de uma sentença temerária.

Estamos verdadeiramente diante de um ciclo: a lei escrita deve instituir a lei natural (concretizá-la) para que tenhamos uma sentença baseada na lei escrita proferida segundo a reta-razão. Se a lei escrita for injusta, por motivo de ter sido promulgada segundo o mero arbítrio do legislador ou por não estar adequada a novos tipos de problemas surgidos em meio à constante escalada evolutiva humana, a sentença baseada nessa lei não será vinculativa ou obrigatória, pois uma lei só encontra força na natureza, e aquilo que contraria o Bem Comum, não tendo fundamento natural, não vincula os indivíduos. ${ }^{10} \mathrm{~A}$ noção do que participa do natural é, portanto, o termômetro do justo e do injusto.

A lei justa de ordenação do convívio social é produzida pelo legislador, obedecendo a um complexo de atos que possam lhe conferir o caráter de vinculatória por ter força natural. Numa primeira fase, chamada intencional, o legislador atua através do intelecto especulativo, escolhendo e elegendo, por um

10. "Dicendum quod lex scripta. sicut non dat rolrer iuri naturali, ita nec potest eitus rlorer minuere vel anferre: quia nec voluntas hominis potest immutare naturam. Ius autem positivum scriptura legis et continet et instituit, dans ei auctoritatis rolrer" Assim, também: "Et ideo, si scriptura legis contineat aliquid contra ius naturale, iniustitia est, nec habet vim obligandi" (Sum. Theol.. II-II, q. LV, art. 6). 
juízo da razão, o meio mais adequado para que se alcance a meta colimada. $\mathrm{Na}$ fase executória, orientado pelo intelecto prático ou agente, ordena aos súditos a execução ou efetivação da intenção eleita primariamente por um ato de imperium, aplica a lei de acordo com o seu fim (usus). Não se pode omitir a promulgação como fase importantíssima para que se dê publicidade ao preceito legislativo.

Se a reta-razão orientou as decisões do legislador que ponderou as escolhas pelo justo meio segundo a lei natural -, orientando as condutas para o Bem Comum, poderá fruir dos benefícios que advirão a esta sociedade, que rapidamente se encaminhará para seu fim.

9. O injusto e os vícios da Justiça

O exercício da Justiça pode ser viciado de muitas maneiras, então, teremos a descaracterização do seu conteúdo. A Justiça distributiva, que consiste na repartição de bens na sociedade civil segundo o mérito de cada qual, estará viciada caso utilize critérios falaciosos de atribuição. Por exemplo, se houver acepção de pessoa segundo sua riqueza na eleição de um cargo profissional, teremos um vício de Justiça. A Justiça comutativa, exercida na distribuição igualitária dos bens nas trocas entre particulares, pode ser viciada de múltiplas maneiras. Assim, pelo furto, pelo roubo, pela prisão arbitrária, pela violência, pela difamação ou pela desigualdade oriunda da violação dos respectivos direitos e deveres em contratos em geral, como compra e venda, locação, depósito, empréstimo e até em usufruto. Todos se regulam pelo princípio de que ambas as partes têm o direito à mesma quantidade (Sum. Theol., II-II, q.61, art. 3).

O homicídio (quaest. LXIV), a violação da propriedade (quaest. LXVI), o julgamento parcial (quaest. LXVII), a acusação mentirosa (quaest. LXVIII), a participação desonrosa do advogado (quaest. LXXI) são todos exemplos de vícios que afetam de maneira direta ou indireta a Justiça.

Mas, se existem vícios que pervertem a Justiça, existem, também, virtudes conexas e mesmo participantes da Justiça como virtude maior, lato sensu. Assim a piedade filial, a religião, a liberalidade, a afabilidade, a veracidade... participam da ordem moral humana, permitindo um relacionamento social 
harmonioso que favoreça o desenvolvimento dos valores humanos mais sublimes dentro da sociedade."

10. Aplicações práticas do conceito de Justiça

A propriedade privada encontra seu fundamento no ius gentium, uma vez que não é algo advindo da natureza, mas decorrente da convenção do homem, do ius positivum. Assim, se foi o direito próprio do homem racional aquele que instituiu a propriedade privada, cabe ao legislador equilibrar uma distribuição eqüitativa da mesma entre os indivíduos, de modo a evitar grandes disparidades sociais.

O matrimônio (matrimonium) é algo proveniente do ius naturale strictissimo modo, ou seja, daquela parte do Direito natural quod omnia animalia docuit. Isto se dá porque o homem integra a família como primeiro núcleo de convívio para depois congregar-se em sociedade. Mas o matrimônio humano difere da união impulsiva e instintiva do animal, pois encontra objetivos outros diferentes da mera procriação: a associação do homem com a mulher e a educação dos filhos. O casamento monogâmico é o próprio para a realização desses valores.

A escravidão é outra instituição do Direito das Gentes, não sendo derivada do Direito natural (quod naturalis ratio inter omnes hominis constituit, na definição do jurisconsulto romano Gaio).

Como decorrência natural de uma variação imensa de conclusões retiradas das premissas gerais do pensamento do Doutor Angélico, encontram-se, ainda, outras aplicações inevitáveis do conceito de Justiça depreendido da forma como foi elucidado. A saber:

a. só o Estado tem o direito de matar em prol da sanidade do corpo social (ius vitae ac necis), amputando-lhe o membro degenerado;

b. a legítima defesa é consentida desde que haja uma proporcionalidade entre reação e ameaça e, também, desde que a pretensão seja a autodefesa e não o assassínio da outra parte;

c. o roubo e o furto não são considerados infrações quando o indivíduo se encontrar em uma situação de necessidade, ou seja, quando sua vida estiver dependendo do objeto do roubo.

11. "Dicendum quod iustitiae. cum sid virtus cardinalis, quaedam aliae virtutes secundariae adiungutur: sicut misericordia, liberalitas et aliae huiusmodi virtutes (...)" (Sum. Theol., II-II, q. LVIIJ, art. 12). 
Estas são as principais contribuições que se poderiam lançar sobre as temáticas aqui lançadas como estimulantes da análise textual da obra tomasiana. Basta, pois, com o que se disse.

São Paulo, dezembro de 1998.

\section{BIBLIOGRAFIA}

AMEAL, João. São Tomás de Aquino. $2^{\mathrm{a}}$ ed., Porto : Livraria Tavares Martins, 1941.

AQUINO, São Tomás. Suma Contra os Gentios. Trad. de Odilão Moura O.S.B. v. I, livros I e II. Rio Grande do Sul : Escola Superior de Teologia São Lourenço de Brindes, Universidade Caxias do Sul, Livraria Sulina Editora, 1990. Suma Teológica. Trad. de Alexandre Correia. vs. II, III e IV $2^{a}$ ed. Rio Grande do Sul : Livraria Sulina Editora e Grafosul Indústria Gráfica Editora, 1980.

Suma Teológica: do direito, da justiça e de suas partes integrantes. Trad. de Alexandre Correia. São Paulo : Livraria Editora Odeon, 1937.

Tratado de la ley; Tratado de la justicia; Gobierno de los príncipes. Quinta edición. Traducción y estudio introductivo por Carlos Ignacio González. México : Editorial Porrúa, 1996.

La justicia: comentários a el libro quinto de la Ética a Nicomaco. Trad. de Benito R. Raffo Magnasco. Buenos Aires, Argentina, 1946.

- Cursus philosophicus thomisticus: Naturalis philosophiae

(secundum exactam, veram, genuinam Aristotelis et Doctoris Angelici mentem). Nova editio. Taurini (Itália) : Ex Officina Domus Editorialis Marietti, 1936.

ARISTÓTELES. Ética Nicomáquea. Ética Eudemia. Madrid : Editorial Gredos: 1993.

. A Ética de Nicômaco. Trad. Cássio M. Fonseca. Biblioteca Clássica, v. XXXIII. São Paulo: Athena Editora, 1940. 
BITTAR, Eduardo C. B. A teoria aristotélica da justiça. In: Revista da Faculdade de Direito da Universidade de São Paulo, v. 92, pp. 53-73. São Paulo, 1997.

COPLESTON, F C. El pensamiento de Santo Tomás. México, Argentina : Fondo de Cultura Econômica, 1960.

CORREIA, Alexandre. Ensaios políticos e filosóficos. São Paulo : Convívio, EDUSP, 1984.

DEL VECCHIO, Giorgio. A justiça. Direção de Miguel Reale. Trad. de Antônio Pinto de Carvalho. Coleção Direito e Cultura. São Paulo : Saraiva, 1960.

GUIMARÃES, Ylves José de Miranda. Direito Natural - visão metafísica e antropológica. Rio de Janeiro : Forense Universitária, 1991.

MARTINELLI, Lucien. Thomas d'Aquin et l'analyse linguistique. Montréal; Paris : Institut d'études médiévales; J. Vrin, 1963.

SERTILlANGES, A. D. La philosophie de S. Thomas d'Aquin. Nouvelle édition, revue et augmentée. Paris : Aubier, 1940.

STEENBERGHEN, F Van. O tomismo. Trad. e prefácio de J. M. da Cruz Pontes. Lisboa: Gradiva, 1990.

VÁRIOS AUTORES. Actas de la XIII reunión de amigos de la Ciudad Católica. Santo Tomás de Aquino, hoy. Madrid : Residência del Pilar, Editora Spliro, noviembre de 1974. 